\title{
Detecção e monitoramento de área de infiltração controlada de vinhaça utilizando o método da eletrorresistividade
}

Walter Malagutti Filho, DGA/IGCE/UNESP - Rio Claro; José Ricardo Melges Bortolin, Pós-Graduação em Geociências/IGCE/UNESP - Rio Claro; César Augusto Moreira, DGA/IGCE/UNESP - Rio Claro; Alice Marques Pereira, Pós-Graduação em Geociências/IGCE/UNESP - Rio Claro.

Copyright 2014, SBGf - Sociedade Brasileira de Geofísica

Este texto foi preparado para a apresentação no VI Simpósio Brasileiro de Geofísica, Porto Alegre, 14 a 16 de outubro de 2014. Seu conteúdo foi revisado pelo Comitê Técnico do VI SimBGf, mas não necessariamente representa a opinião da SBGf ou de seus associados. É proibida a reprodução total ou parcial deste material para propósitos comerciais sem prévia autorização da SBGf.

\section{Resumo}

Um projeto de infiltração controlada de vinhaça e posterior detecção e monitoramento da pluma de contaminação foi desenvolvido em uma área de estudos situada sobre sedimentos predominantemente arenosos da Formação Pirambóia. Três diferentes volumes de vinhaça $(60,300$ e 900 litros) foram infiltrados e o comportamento do contaminante em subsuperfície foi monitorado por meio de diversos métodos geofísicos. O volume mínimo a ser infiltrado foi estabelecido com base nas características químicas do solo do local e da vinhaça. Os resultados obtidos com o método da eletrorresistividade (ER) revelam a eficácia do método para esta finalidade e o qualificam como uma opção expedita e de baixo custo operacional para o diagnóstico ambiental de áreas impactadas. A intensidade das anomalias observadas é diretamente proporcional ao volume de vinhaça infiltrado, devido à maior quantidade de substâncias eletricamente condutoras transferidas ao solo.

\section{Introdução}

Desde o período colonial, a agricultura constitui uma das bases da economia brasileira. Atualmente, a cana-de-açúcar representa um dos mais importantes produtos agrícolas do país.

O Brasil é o maior produtor mundial de cana-de-açúcar, de açúcar obtido a partir da cana e, também, o maior exportador mundial de açúcar (ISO, 2009). Somente o Estado de São Paulo concentra 52,07\% da área cultivada nacional, tornando-se responsável por $56,15 \%$ de toda a cana colhida no país. Na safra 2012/2013, as usinas paulistas produziram 23.351.700 toneladas de açúcar e 12.198.507.700 litros de etanol (Conab, 2013).

Dentre os resíduos do processo de produção do etanol, destaca-se a vinhaça, substância líquida gerada na proporção aproximada de 13 litros de vinhaça para cada litro de etanol. No Brasil, este resíduo é utilizado como fertilizante em lavouras de cana-de-açúcar, pois é rico em nutrientes minerais (principalmente $\mathrm{K}^{+}, \mathrm{Na}^{+}, \mathrm{Mg}^{2+} \mathrm{e} \mathrm{Ca}^{2+}$ ). Entretanto, o excesso de vinhaça pode causar contaminação do solo e da água subterrânea, fato recorrente no país e que requer estudos que conduzam a uma metodologia de detecção e monitoramento do volume ideal a ser disposto no meio.

De um modo geral, investigações da influência da vinhaça em solos e águas subterrâneas são efetuadas por meio de análises físico-químicas em amostras coletadas em áreas de cultivo de cana-de-açúcar, onde é praticada a fertirrigação - Ludovice (1997); Lyra, Rolim e Silva (2003); Silva et al. (2006); Brito, Rolim e Pedrosa (2007) - ou em áreas de sacrifício, onde é feita a infiltração - Hassuda (1989).

Entretanto, os métodos tradicionais de investigação acabam por encarecer e aumentar demasiadamente o tempo de execução de estudos em grandes áreas, já que se torna necessário coletar e analisar um grande número de amostras, ou ainda, construir inúmeros poços de monitoramento, de modo que possam abranger toda a extensão da área em questão.

Por outro lado, os métodos geofísicos mostram-se como uma opção eficiente e interessante para a investigação de áreas que tenham sido contaminadas pela infiltração da vinhaça. Uma das principais vantagens destes em relação aos métodos tradicionais de investigação de subsuperfície é a rapidez na avaliação de grandes áreas com custo relativamente menor. Além disso, são de natureza não invasiva, o que significa que, a priori, não alteram o meio físico.

Porém, são escassas as propostas metodológicas envolvendo métodos geofísicos, tanto como ferramenta auxiliar quanto como principal, na investigação de contaminação causada pela disposição irregular de vinhaça - Mendes (1987), Gloeden et al. (1991) e Cruz (2008).

Assim, a principal proposta deste trabalho é caracterizar o tipo de anomalia geofísica inerente à infiltração controlada de vinhaça em uma área de sedimentos arenosos e monitorar a pluma do contaminante, mediante a utilização do método da eletrorresistividade.

\section{Metodologia}

Uma área de estudos de $100 \mathrm{~m}^{2}(10 \mathrm{~m} \times 10 \mathrm{~m})$ e com declividade aproximado de $34^{\circ}$ foi selecionada em uma propriedade da zona rural do município de Corumbataí (SP) (Figura 1).

Localmente, ocorrem sedimentos pertencentes à Formação Pirambóia (período triássico), a qual é constituída basicamente por arenitos médios e finos, podendo ocorrer intercalações de finas camadas de argilitos e siltitos. Sotoposta a esta, ocorre a Formação Corumbataí (período permiano superior), regionalmente representada por argilitos e siltitos de diversas colorações.

No local, foram abertas duas valas medindo, aproximadamente, $0,45 \mathrm{~m} \times 0,45 \mathrm{~m} \times 2,00 \mathrm{~m}$ (volume total aproximado $=405$ litros), por onde foi executada a infiltração 
controlada do contaminante. A área escolhida não apresenta histórico de infiltração de vinhaça.

$A$ vala $A$ foi posicionada no extremo esquerdo da área de estudos, enquanto que a vala B ocupou a porção central. A distância entre elas é de $2 \mathrm{~m}$ e ambas localizam-se $5 \mathrm{~m}$ à jusante do limite superior da área.

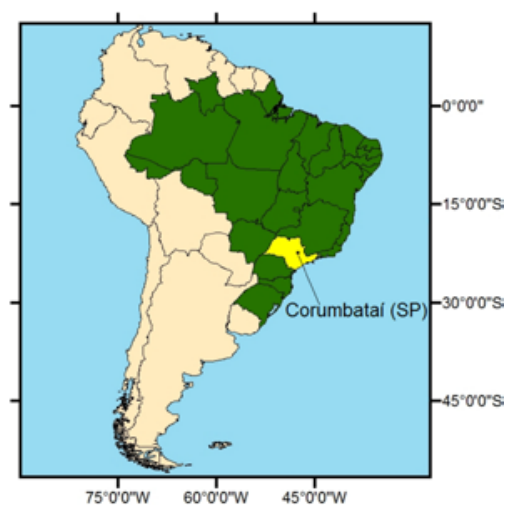

Figura 1: Localização da área de estudos.

\section{Método da Eletrorresistividade (ER)}

O método da eletrorresistividade (ER) baseia-se no fato de que diferentes materiais, geológicos ou não, apresentam diferentes valores de resistividade elétrica ( ), parâmetro intrínseco dos materiais que indica a maior ou menor dificuldade encontrada por uma corrente elétrica para se propagar em um meio. Esse coeficiente depende, entre outras coisas, da natureza e do estado físico do corpo considerado.

Para se determinar o valor de resistividade elétrica que caracteriza um meio geológico é necessário submetê-lo a um campo elétrico. Especificamente para este método, utiliza-se o procedimento galvânico, onde um par de eletrodos metálicos (A e B) é disposto na superfície terrestre e conectados a uma fonte de corrente contínua ou variável. Surge, então, um campo eletromagnético em subsuperfície que gera uma diferença de potencial, a qual pode ser medida entre outro par de eletrodos (M e N) (Telford,

A aquisição dos dados foi feita com um resistivímetro ABEM Terrameter SAS 4000. Duas técnicas foram empregadas neste trabalho: Sondagem Elétrica Vertical (SEV) e Imageamento Elétrico (IE).

A técnica da SEV (investigação da variação da resistividade elétrica, em profundidade, a partir de medidas efetuadas na superfície do terreno) foi desenvolvida empregando-se o arranjo Schlumberger. Neste arranjo, a distância entre os eletrodos de corrente $(\mathbf{A B})$ e os eletrodos de potencial (MN) deve obedecer à relação geométrica (Equação (1)):

$$
M N \leq \frac{A B}{5}
$$

O fator geométrico $\left(K_{S}\right)$ para esse arranjo é dado pela Equação (2):

$$
K_{S}=\pi \frac{(A M \cdot A N)}{M N}
$$

A técnica do IE, neste caso, envolve a medição de valores de resistividade elétrica e de cargabilidade a partir da superfície terrestre e ao longo de uma seção a uma ou mais profundidades determinadas.

Para a aquisição dos dados, optou-se pelo arranjo DipoloDipolo, com 8 níveis de investigação $(n)$. Neste arranjo, os eletrodos de corrente (A e B) e os eletrodos de potencial (M e N) são dispostos sobre uma mesma linha reta imaginária e o espaçamento entre os eletrodos obedece à relação $x=A B=M N$. Os pontos de investigação correspondem ao cruzamento de segmentos de reta que partem do centro geométrico de $\mathbf{A B}$ e de $\mathbf{M N}$, com inclinação de $45^{\circ}$ em relação à superfície.

O fator geométrico $\left(K_{D D}\right)$ para o arranjo Dipolo-Dipolo é dado pela Equação (3):

$$
K_{D D}=2 \pi x \frac{1}{\left(\frac{1}{n}-\frac{2}{n+1}+\frac{1}{n+2}\right)}
$$

onde o coeficiente $n$ representa o nível de investigação e pode assumir somente valores inteiros $(n=1,2,3, \ldots)$.

Os ensaios geofísicos foram divididos em duas etapas: (1) pré-infiltração: desenvolvida de modo a se conhecer valores característicos do ambiente natural isento de contaminação por vinhaça e testar os procedimentos de campo de modo a otimizar a coleta de dados na fase posterior; (2) pós-infiltração: repetição sistemática dos ensaios, objetivando estabelecer um monitoramento temporal da área de estudo após sua contaminação controlada por vinhaça. A Tabela 1 resume as características dos ensaios executados.

Tabela 1: Ensaios geofísicos realizados nas Áreas 1 e 2 (etapa pré-infiltração).

\begin{tabular}{ccc}
\hline Etapa & Ensaio & Quantidade \\
\hline Pré-infiltração & SEV & $\begin{array}{c}\text { 3 com AB/2 máximo de } \\
100 \mathrm{~m}\end{array}$ \\
\cline { 2 - 3 } & IE & $\begin{array}{c}5 \text { linhas com } x=3 \mathrm{~m} \\
1 \text { linha com } x=5 \mathrm{~m}\end{array}$ \\
\hline Pós-infiltração & SEV & - \\
\cline { 2 - 3 } & IE & 3 linhas com $x=2 \mathrm{~m}$ \\
\hline
\end{tabular}

\section{Resultados}

Pré-infiltração

As SEV permitiram inferir a profundidade do nível freático regional entre 6 e 11m. Especificamente na área de estudos, este situa-se a, aproximadamente, 8,6m. Além 
destas informações, por meio das SEV foi possível identificar 7 camadas geoelétricas, das quais as 5 primeiras (1 $1^{\mathrm{a}}$ : sedimentos compactados; $2^{\mathrm{a}}$ : evapotranspiração; $3^{\mathrm{a}}$ : retenção; $4^{\mathrm{a}}$ : capilar; $5^{\mathrm{a}}$ : nível freático) foram interpretadas como uma seqüência de sedimentos predominantemente arenosos da Formação Pirambóia e as camadas 6 e 7 foram associadas aos sedimentos predominantemente silto-argilosos da Formação Corumbataí.

Os resultados dos IE (Figuras 2 e 3) sugerem um cenário idêntico ao identificado com as SEV, sendo possível identificar 3 zonas: (a) evapotranspiração: associada aos valores da ordem de $500 \Omega$.m que ocorrem superficialmente; (b) retenção: porção onde $500 \Omega \cdot m \leq \rho \leq 10.000 \Omega$.m; (c) saturada: faixa onde $\rho \leq 100 \Omega$.m na porção basal da seção.

\section{Pós-infiltração}

A fase pós-infiltração foi iniciada no dia imediatamente posterior à infiltração de $60 \mathrm{~L}$ de vinhaça na vala $\mathrm{A}$ e de $300 \mathrm{~L}$ na vala $B$. Durante as três primeiras semanas do monitoramento, os ensaios geofísicos estenderam-se ao longo dos $20 \mathrm{~m}$ do eixo maior da área (Figura 2). Após este período, o comprimento da área de estudos foi reduzido para os primeiros $10 \mathrm{~m}$ do mesmo eixo, pois os dados mostraram contrastes restritos ao entorno das valas. A largura da área não sofreu alterações.

Os ensaios geofísicos pós-infiltração consistiram em 3 IE e 6 IEM, conforme a Figura 3. No caso dos IE, as Linhas A e B (as quais interceptam as valas homônimas) foram repetidas sistematicamente, enquanto que a Linha de referência foi executada somente uma vez.

A Figura 4 apresenta algumas seções representativas dos resultados obtidos com a técnica de IE. Na Figura 4a, correspondente à seção da Linha de referência executada em local isento de contaminação, observa-se a predominância de valores de $\rho \geq 500 \Omega$.m, associados aos sedimentos predominantemente arenosos da Fm. Pirambóia. Na porção basal da seção, ocorre uma faixa de $\rho \leq 100 \Omega$.m que, no contexto da área, corresponde ao início da zona saturada.

A Figura 4b corresponde à seção da Linha A executada 1 dia após a infiltração de $60 \mathrm{~L}$ de vinhaça na vala em questão. Os valores de resistividade das adjacências da vala A mantiveram-se sempre acima de $500 \Omega$.m, tal como na seção da Linha de referência. Aparentemente, o volume infiltrado não impactou o meio natural a ponto de gerar uma região de contrastes, detectável pelo método ER.

A Figura 4c corresponde à seção da Linha B executada 3 dias após a infiltração de $300 \mathrm{~L}$ de vinhaça na vala em questão. Nela, observa-se uma anomalia posicionada logo abaixo da vala, que atinge cerca de $1,4 \mathrm{~m}$ de profundidade e, aproximadamente, $2,5 \mathrm{~m}$ de extensão lateral, onde $\rho_{\min }=150 \Omega . \mathrm{m}$.

$\mathrm{Na}$ Figura 4d, correspondente à seção da Linha $\mathrm{B}$ executada 8 dias após a infiltração de 900L de vinhaça na respectiva vala, é possível observar uma anomalia situada abaixo da vala, com $\rho_{\min }=50 \Omega . \mathrm{m}$, profundidade máxima em torno de 1,9m e, aproximadamente, 5,0m de extensão lateral.

\section{Discussão e Conclusões}

Relativamente ao background da área, as regiões anômalas exibem menor resistividade, atingindo o mínimo de $100 \Omega$.m. Resultados semelhantes obtiveram Cruz et al. (2008), que caracterizaram a influência da vinhaça no solo por reduzidos valores de resistividade. Segundo os autores, os baixos valores de resistividade são atribuídos à influência dos sais e à retenção de água pela matéria orgânica, ambos presentes em elevadas quantidades na vinhaça.

No caso de sedimentos arenosos, como na Área 2, a adsorção dos cátions $\mathrm{Ca}^{2+}, \mathrm{Mg}^{2+}, \mathrm{K}^{+}$e $\mathrm{Na}^{+}$é significativamente reduzida devido à proporcionalmente baixa capacidade de troca catiônica (CTC). Deste modo, a propagação de correntes elétricas injetadas é facilitada pela presença de partículas eletricamente condutoras. Por isso, quanto maior é o volume de vinhaça infiltrado, mais intensas são as anomalias, devido à maior quantidade de substâncias eletricamente condutoras transferidas ao solo.

\section{Agradecimentos}

Os autores agradecem à Fundação de Amparo à Pesquisa Científica do Estado de São Paulo - FAPESP pelo suporte financeiro (processo 2011/21659-5).

\section{Referências}

Brito, F. L.; Rolim, M. M.; Pedrosa, E. M. R., 2007. Concentração de cátions presentes no lixiviado de solos tratados com vinhaça. Revista Engenharia Agrícola, Jaboticabal, v. 27, n. 3: 773-781.

Conab - Companhia Nacional de Abastecimento, 2013. Acompanhamento da safra brasileira: cana-de-açúcar: safra 2012/2013. Disponível em: <http://www.conab.gov.br/OlalaCMS/uploads/arquivos/13_0 4_09_10_30_34_boletim_cana_portugues_abril_2013_40_I ev.pdf>. Acessado em: $1 \overline{6}$ abr. 2013.

Cruz, J. I., 2008. Detecção da influência da vinhaça na resistividade do solo através da análise de dados geofísicos: um estudo de caso no assentamento Sepé Tiarajú - SP. Dissertação (Mestrado em Geociências) Instituto de Geociências, Universidade Estadual de Campinas, Campinas.

Cruz, J. I. et al., 2008. Detecção de contaminação de solo por vinhaça através de análise de dados de eletrorresistividade. Revista Brasileira de Geofísica. v.26, n.4: 481-492.

Gloeden, E.; Cunha, R. C. A.; Fraccaroli, M. J. B.; Cleary, R. W., 1991. The behaviour of vinasse constituents in the unsaturated and saturated zones in the Botucatu aquifer 
recharge area. Water Science Technology, v. 24, n. 11: 147-157.

Hassuda, S., 1989. Impactos da infiltração da vinhaça de cana no Aqüífero Bauru. Dissertação (Mestrado). Instituto de Geociências, Universidade de São Paulo, São Paulo.

ISO - International Sugar Organization, 2008. Sugar Year

Book 2008. Disponível em:

<http://www.isosugar.org/PDF\%20files/SUGAR\%20YEAR\%

20BOOK\%20-\%20sample.pdf>. Acessado em 16 abr. 2013.

Ludovice, M. T. F., 1997. Estudo do efeito poluente da vinhaça infiltrada em canal condutor de terra sobre lençol freático. Dissertação (Mestrado em Engenharia Civil) - Programa de Pós-Graduação em Engenharia Civil, Universidade Estadual de Campinas, Campinas.

Lyra, M. R. C. C.; Rolim, M. M.; Silva, J. A. A., 2003.

Toposseqüência de solos fertigados com vinhaça:

contribuição para a qualidade das águas do lençol freático.
Revista Brasileira de Engenharia Agrícola e Ambiental, Campina Grande, v. 7, n. 3: 525-532.

Mendes, J. M. B., 1987. Técnicas geofísicas aplicadas no mapeamento e monitoramento de poluição e contaminação de águas subterrâneas. 196f. Tese (Doutorado em Geociências) - Instituto de Geociências, Universidade de São Paulo, São Paulo.

Silva, A. J. N.; Cabeda, M. S. V.; Carvalho, F. G.; Lima, J. F. W. F., 2006. Alterações físicas e químicas de um Argissolo amarelo sob diferentes sistemas de uso e manejo. Revista Brasileira de Engenharia Agrícola e Ambiental, v. 10, $n$. 1: 76-83.

Telford, W. M.; Geldart, L. P.; Sheriff, R. E., 1990. Applied Geophysics. 2. ed., University Press, Cambridge.
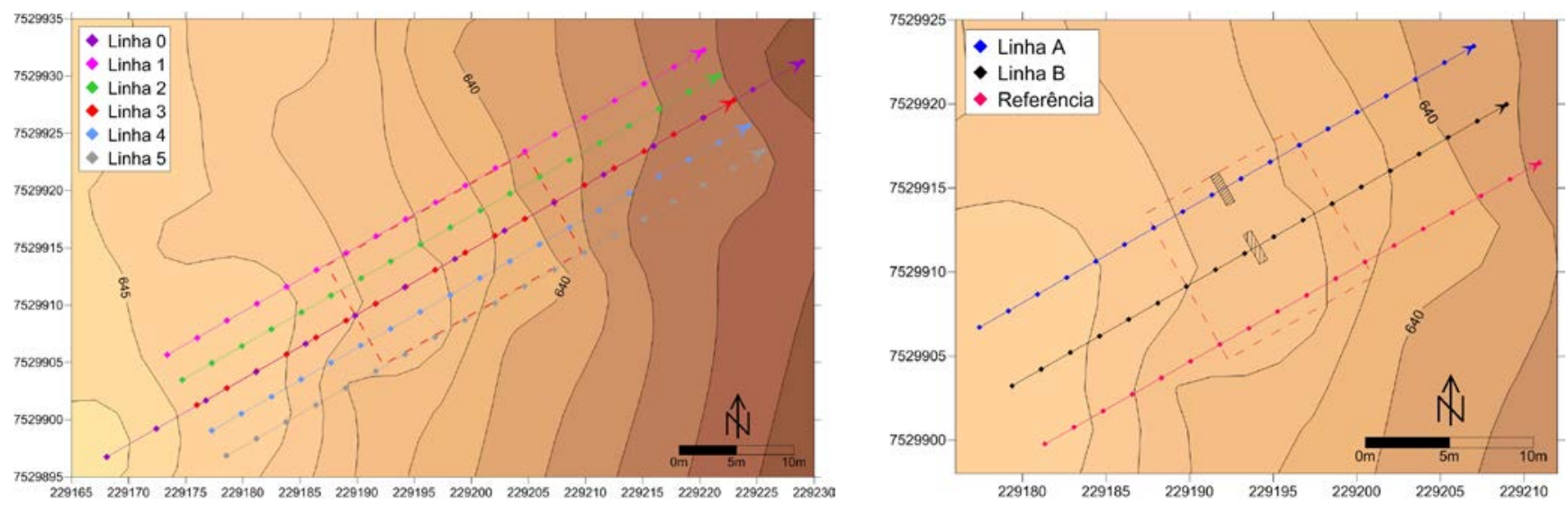

Figura 2: Mapa de localização dos Imageamentos Elétricos. À esquerda: pré-infiltração. À direita: pós-infiltração.

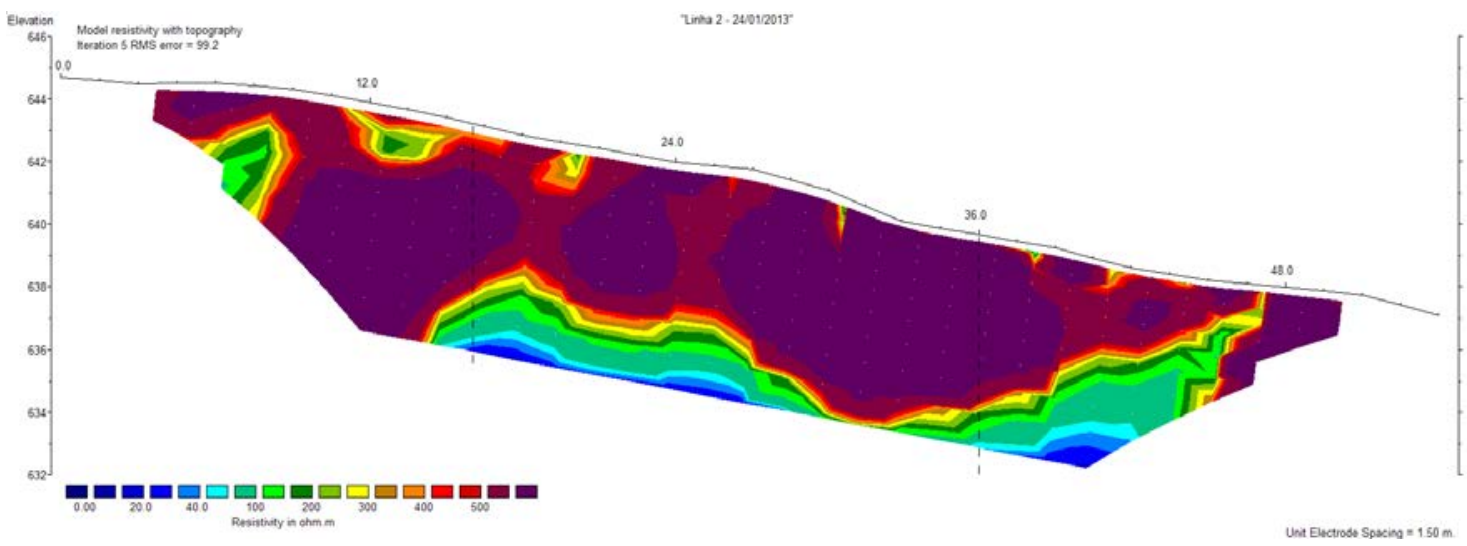

Figura 3: Seção típica de resistividade elétrica pré-infiltração. 


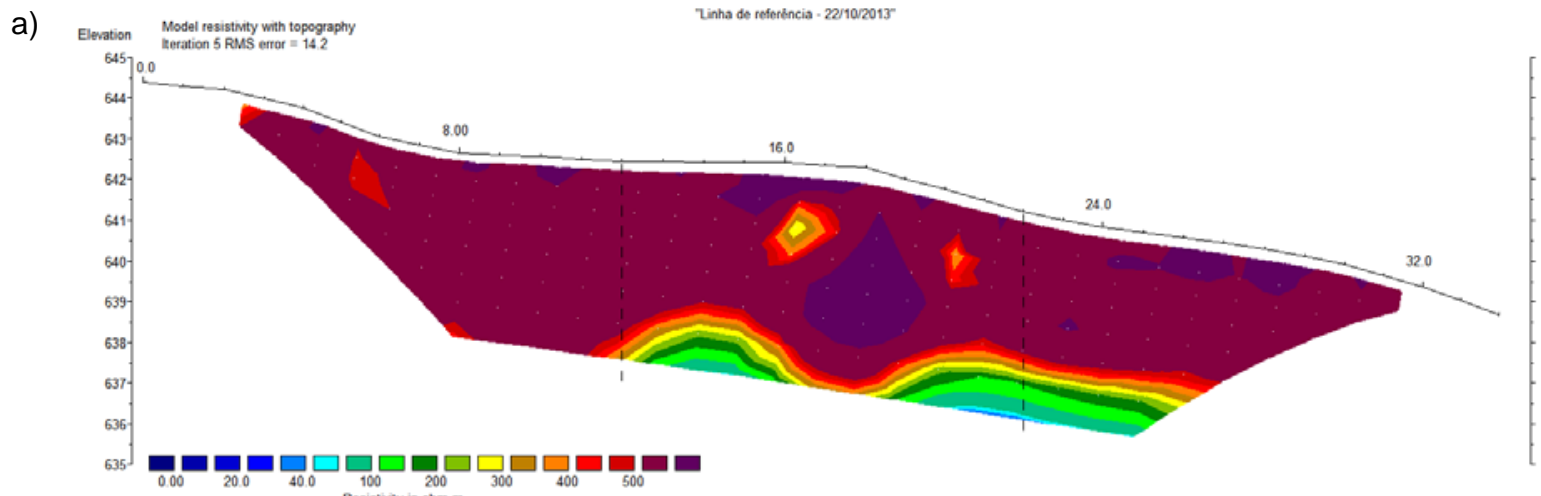

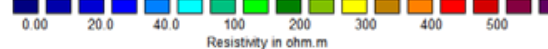

Unit Electrode Spacing $=1.00 \mathrm{~m}$
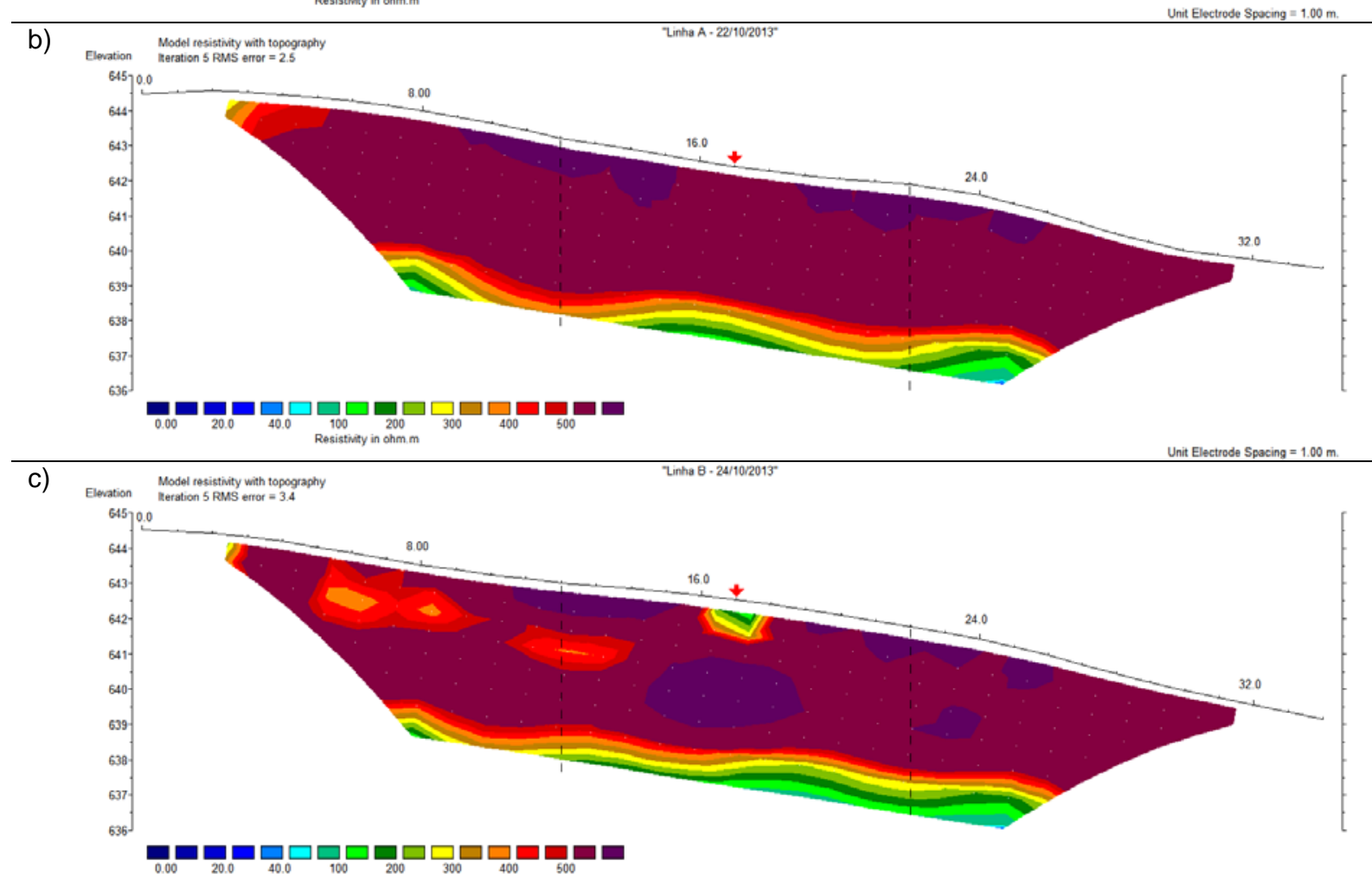

$0.00 \quad 20.0 \quad{ }_{40.0} \underbrace{}_{100} \underset{200}{ }{ }_{300}{ }_{400}{ }_{500}$

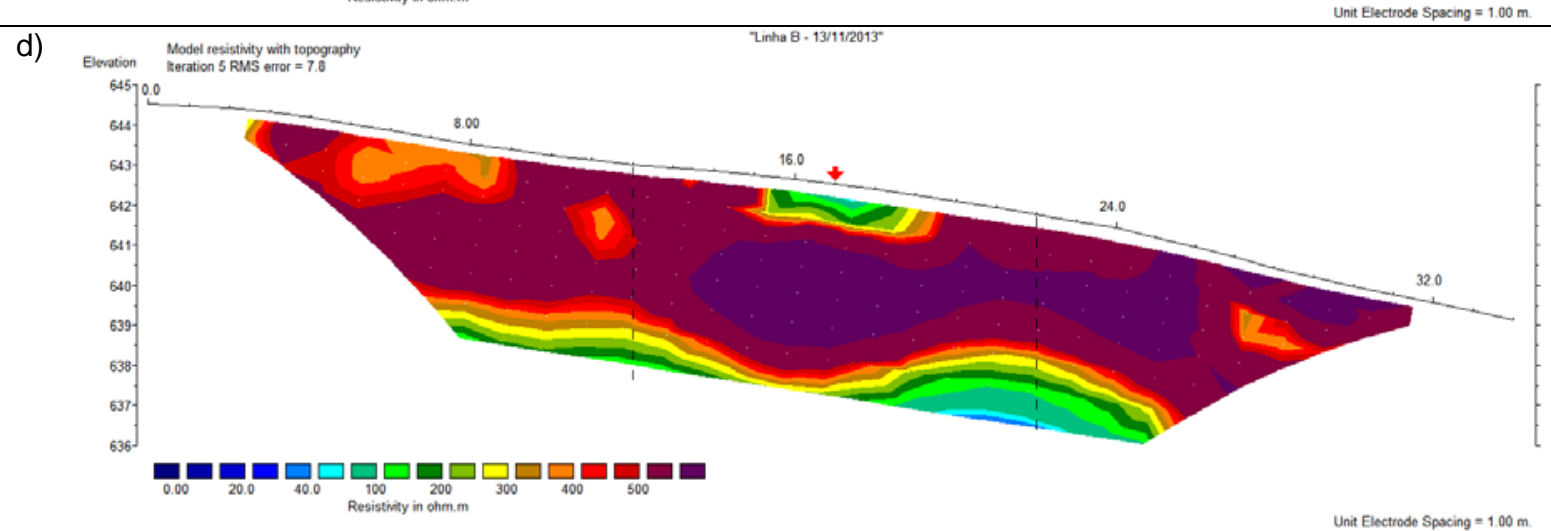

Figura 4: Seções de resistividade representativas das linhas de IE. A seta vermelha indica a posição das valas. As linhas pretas pontilhadas definem os limites da área de estudos. 